\title{
Rapid prototyping model for the manufacturing by thermoforming of occlusal splints
}

\author{
M. Fiménez \\ Department of Mechanical Engineering, Technical School of Engineering - ICAI, Comillas University, Madrid, Spain, and \\ L. Romero, M. Domínguez and M.M. Espinosa \\ Department of Construction and Manufacturing Engineering, School of Industrial Engineering - UNED, Madrid, Spain
}

\begin{abstract}
Purpose - This paper aims to present an optimal prototyping technology for the manufacture of occlusal splints.

Design/methodology/approach - To carry out this study, a comparative technique was used to analyze models obtained by different prototyping techniques. Subsequently, further tests were carried out with respect to the manufacturing of splints by means of thermoforming in a vacuum. This involved an analysis of the most important variables such as prototype material, geometric accuracy, surface finish and costs.

Findings - It was found that there is a group of prototyping technologies that are suitable for the manufacture of the models used in the thermoforming of correction splints, the most appropriate technologies being based on ink jet printing (IJP-Objet), ultraviolet photo polymerization and fused deposition modelling due to the fact that they offer an optimal relationship between the cost and the quality of the model required for thermoforming.

Practical implications - The application of rapid prototyping techniques in medicine makes the production of physical models from three-dimensional medical image processing and their subsequent use in different specialties possible. It also makes preoperative planning processes, the production of prostheses and the preparation of surgical templates possible, thereby offering a higher quality of diagnosis, safer surgery and cost and time savings compared to conventional manufacturing technologies.

Originality/value - This paper suggests that there exists a group of prototyping technologies for the manufacture of splints that offer advantages over existing technologies. The results also suggest that, in many cases, the most expensive technology is not the most appropriate: there are other options that provide an optimal model in terms of the cost and the quality needed for thermoforming.
\end{abstract}

Keywords Rapid prototyping, Invisible orthodontic, Operative dentistry, Splints, Thermoforming

Paper type Research paper

\section{Introduction}

In recent years, there have been significant developments in the industrial applications used in rapid prototyping (RP), reverse engineering (RE) and computer-aided manufacturing (CAD/CAM) design technology in the field of dentistry (Gracco et al., 2008; Azari and Nikzad, 2009).

These applications reduce the treatment time for patients for most of the techniques used in orthodontics and dental services. Currently, their use is focused on the design and manufacture of corrective appliances, the planning and simulation of corrective treatments and the design and manufacture of dental prostheses (Liu et al., 2006; Germani et al., 2010).

One method of realigning teeth in a short period of time at a reduced cost is through the use of occlusal splints. These splints are obtained by a thermoforming process under

The current issue and full text archive of this journal is available on Emerald Insight at: www.emeraldinsight.com/1355-2546.htm

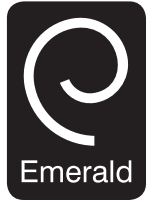

Rapid Prototyping Journal

21/1 (2015) 56-69

C Emerald Group Publishing Limited [ISSN 1355-2546]

[DOI 10.1108/RPJ-11-2012-0101] pressure or vacuum, which uses a physical model obtained from a given prototyping technology. It is very important to note that the technology used to generate the model determines the quality of the splint in terms of its dimensional accuracy, surface quality, thickness variation and cost. Given the increase in alternative orthodontic treatments based on thermoplastics devices, it would seem appropriate to analyze and describe the performance of the devices currently available with respect to the manufacturing of dental models and the dimensional characteristics of the thermoplastic material (Wolfram et al., 2009).

Current RP technologies are additive, and they are based on the dispersion-accumulation principle. The objects to be prototyped are modeled in three-dimensions (3D) using CAD. After that, the model is sliced into a series of thin flat layers, which are then stacked together to form the physical body.

The work presented was carried out within the cooperation agreement established between the following entities: National University of Distance Education (UNED), Pontifical University Comillas of Madrid and Aragoneses Dental Center.

Received 12 November 2012

Revised 6 June 2013

Accepted 7 July 2013 
There are several criteria for the classification of prototyping technologies:

- materials: plastics, ceramics or metals;

- ground state of the material: liquid, solid or powder; and

- principle used in the deposition of the material.

For the last criterion, the most important technologies used for RP are based on the following two principles (Yongnian et al., 2009):

1 techniques based on a beam or high-energy light: stereolithography (SLA), solid ground curing (SGC), inkjet printing (IJP) or selective laser sintering (SLS); and 2 techniques based on injection or extrusion of material: fused deposition modeling (FDM) or 3D printing (3DP).

The analysis of the variables that usually influence the decision about the prototyping technology to be used depending on resolution, precision of the mechanical and thermal properties of the material, surface finish, execution time and the cost of the prototype (Masood and Soo, 2002).

Most RP systems use a faceted file format to obtain the model geometry, and the default standard is STereo Lithography (STL). The faceted model is created by mapping a triangular mesh over a surface or solid model. This produces an approximation to the original CAD model and can affect the quality of the surface of the final product (Hope et al., 1997).

The prototype of the final model is used to thermoform a prefabricated thermoplastic sheet that is fixed in one position and is heated to its softening temperature (Throne, 1987; Delorenzi and Nied, 1987). The softened sheet is shaped using the model and by applying vacuum (vacuum forming) or using a light positive pressure (pressure forming).

The thermoformed components have several limitations such as variations in the thickness of the sheet, especially in areas formed at the end of the process (Nam et al., 2000; Ayhan and Zhang, 2000).

Depending on the initial thickness of the sheet, a variation in thickness has a direct effect on the properties of the splint, tenacity resistance and permeability, which may result in a poor quality splint. The stretching process and distribution of the wall thickness of the thermoplastic sheet can be predicted from models already defined (Hosseini et al., 2006).

There are several previous studies which illustrate that the models obtained using RP have an average error in most dimensions of $0.05 \mathrm{~mm}$ with respect to the original model or control (Taft et al., 2011).

This study is an approach to the problem of the selection of optimal prototyping technology to obtain the model used in the thermoforming process of correction splints. Both tests for the production of thermoformed splints and subsequent surface dimensional verification were carried out.

The quality of the thermoformed sheet depends on the prototyping technology used to obtain the model. The prototyping technologies analyzed are based on the deposition of the material in layers, and because of the adhesion produced during the vacuum, an exact footprint of the surface of the model is left on the sheet and there is a variation in the cooling speed, depending on the degree of porosity of the model, factors that clearly affect the quality of the thermoformed sheet.

\section{Materials and methods}

\subsection{Conventional splint vs digital splint models}

The conventional process of dental splint fabrication is as follows (Yanping et al., 2006):

- first, the plaster cast is molded;

- second, the occlusal models are mounted on an articulator;

- third, the osteotomy is simulated in accordance with the results of the two-dimensional cephalometric, and the form of the model is definitively fixed such that a good occlusal connection can be maintained; and

- finally, a quantity of self-congealable plastic is placed on the lower teeth arch, and the upper teeth and lower teeth are occluded to form the plastic dental splint.

In the process of molding the plaster cast, the mold should be accurate and leave enough space for extension, the surface of the plaster cast should be smooth and the teeth should not have flaws or air bubbles. During the mounting of the occlusal models on an articulator, the position of the model must be definitively fixed in three dimensions (on the sagittal, coronal and horizontal planes). Otherwise, the positional error will affect the occlusal function. This process is troublesome, and the difference between the model surgery and the surgical result ranges from -7.7 to $6.6 \mathrm{~mm}$ (Kwon et al., 2002). This shows that further development of the maxillary positioning system is required, namely, in the design and fabrication of the dental splint.

The digital splint model is a method based on computer-assisted 3D simulation and RP technology, and the splints are obtained by a vacuum pressure thermoforming process. The main advantages of this second method are a clear reduction in operating time (given that the majority of the stages of the prosthetic process are eliminated) and a major improvement in the accuracy of the models $(<1.5 \mathrm{~mm})$. Although it is possible that there will be a slight increase in costs, this will depend, to a large extent, on the prototyping technology selected for use.

The aim of this article is to assist in the choice of the most appropriate for the production of dental splints. To this end, it will be necessary to analyze the methodology of the prototyping technology and the different RP technologies that should be obtained, examine the thermoforming process and carry out tests on dental splints placed in the mouths of patients.

\subsection{Development and methodology}

With the objective of selecting a prototyping technique suitable for obtaining models for dental thermoformed splints, the schedule shown in Figure 1 was carried out.

When the patient visits the orthodontist for the first time, the latter studies the case using photographs, mold testing and the patient's mouth print. Then, the mold is sent to the laboratory, where the transparent splints are made.

The process of taking an impression of the mouth produces a model, usually made of plaster and free of sharp areas. The ideal process is based on direct scanning in the mouth, which can provide an image of the distribution of the teeth in the form of a cloud of points. This image will be used for further digital processing and to obtain the $3 \mathrm{D}$ model. Thus, the 
Figure 1 Process study (experimental design)

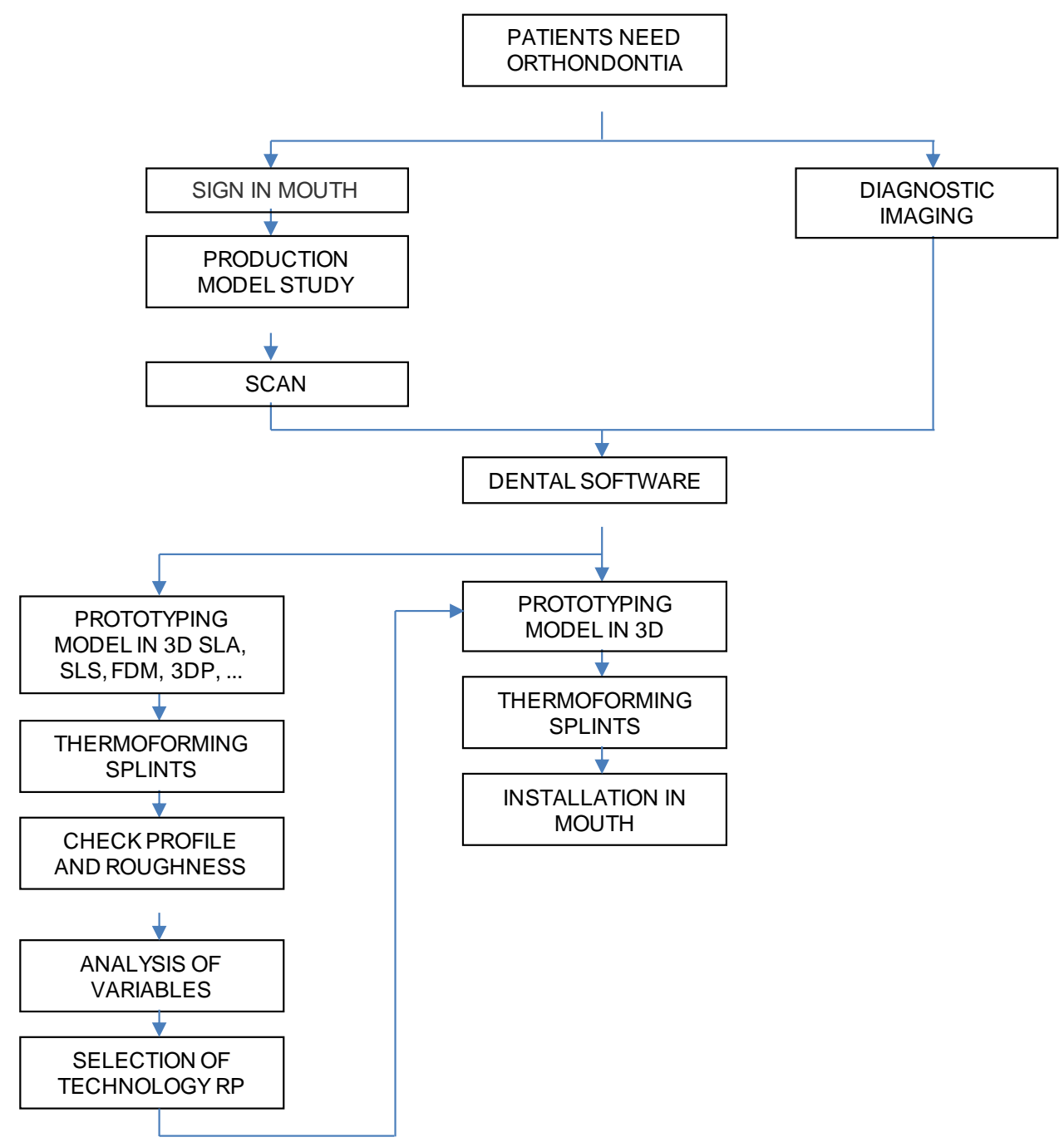

phases of taking an impression and obtaining a model can be optimized by using RE and RP (Germani et al., 2010).

When the 3D model has been obtained, decisions are taken regarding the separation of the teeth and progressive placement, and a simulation of the movement of the teeth is created to correct their alignment. This simulation indicates how many splints are necessary to obtain the sequence that the patient's teeth require. Each splint corresponds to a phase of motion and requires a $3 \mathrm{D}$ model for its manufacture (Boyd and Vlascalic, 2001).

The splints must:

- permit stable contact between the teeth;

- be aesthetically pleasing;

- not hinder speech;

- not affect the mucosa;

- offer occlusal stability;

- have the required vertical dimensions; and

- offer dimensional stability.

The manufacturing process of the model must meet the requirements for providing the required functionality: the accuracy of the dimensions, geometry and surface hardness and appropriate porosity and thermal resistance.

In this study to check that these requirements have been complied with, dental models manufactured by different prototyping technologies were used. The requirements in terms of geometric precision, surface finish, thermal resistance and porosity were controlled for, and, subsequently, the correction splints were manufactured by means of thermal forming. Finally, the required resistance and surface finish were verified again.

Correction splint functionality tests were carried out with eight patients, with five splints for each patient. The results are being commented upon in this article.

\subsection{Analysis of RP technologies for dental models}

Nowadays, prototyping machines meet the following requirements: high-speed manufacturing, use of various types of materials, controlled communication by computer via standard interfaces, lower manufacturing costs, minimal environmental impact and low noise. 
The prototype mechanical properties obtained by the addition of material are conditioned by the quality of the contact between layers and the properties of the base material (Vargas and Córdoba, 2004). To analyze the mechanical and thermal properties of the materials used in the diverse RP methods, the following parameters must be complied with (ASTM-D256 -D638 -D648 $\quad$-D790 -D792 $\quad$-D785, DIN-EN-ISO 178/ 179/ 180/ 527/ 2039/ 53,466): modulus of elasticity, tensile strength, elongation, flexural modulus, impact strength, compressive strength, melting point, density and hardness.

To produce models for manufacturing thermoformed parts in small series, RP technology based on the deposition of a fused wire (FDM), SLA, SLS, SGC or 3DP is used.

For the development of this study, the most important prototyping technologies based on processes of the addition of material were analyzed. As for material removal technologies, no data concerning the use of thermoformed splint models obtained by machining are presented. However, the machining technology of milling is included to provide a further point of comparison. The technologies analyzed are:

- SLA;

- SLS;

- FDM;

- $\quad$ SGC;

- IJP);

- 3DP; and

- milling machining.

The selection of the most appropriate technique for each kind of prototype is based on the definition of the objective to be achieved with that prototype: aesthetic, functional, experiential or visual (to see the result of the design process). The selection can be based on an analysis of the most important variables: technology, resolution, accuracy, materials, software, mechanical properties (tensile, compression, impact, softening and density), surface finish, execution time, cost, overall dimensions of the part or model, post-curing requirements, security, noise, operating temperature, connections and power consumption, interface (network, hardware, software and swap formats), weight, spare parts and consumables.
To detect the impact of RP in the manufacturing process of correction splints, it is necessary to review the different techniques that are currently used:

- Simplified or direct technique: The splint is made from self-curing acrylic without articulation or assembly. The occlusal adjustments are made directly when the splint is being fitted in the patient's mouth.

- Indirect technique: The splint is made with heat-curable acrylic using the following process: impression, obtaining a working model, block, board layout, muffled wax, wax removal, preparation and application of acrylic, honing, polishing and testing in the mouth.

- Thermoforming technique: In this case, rigid acetate sheets are used. The process is as follows: impression, working model in plaster block and design, thermoforming under vacuum or pressure, polishing and testing in the mouth to check the fit of the teeth, jaw retention and stability.

\subsection{Vacuum thermoforming}

Vacuum thermoforming is a manufacturing process in which a sheet is heated to a malleable forming temperature, formed to a specific shape in a mold and trimmed to create a usable product. The sheet is heated at the top of the machine to a temperature which is sufficiently high to enable it to be stretched onto a mold and, after that, cooled to a finished shape.

In the thermoforming process, thermoplastic polymers can be used, but it is essential to know their thermal properties. The softening temperature is the most critical factor (Table I).

The process of heating the thermoplastic sheet requires a significant period of time. It can be carried out by contact, dipping, convection or infrared radiation. With regard to temperatures and the forming cycle, the recommended limits are indicated in Table II:

- Demolding temperature: The piece can be removed from the mold without distortion.

- Lower limit of operation: The material is formed without internal stress.

- Forming temperature: All parts of the sheet reach the desired temperature and can thus be formed using a standard procedure.

- Upper limit: The sheet begins to deteriorate; it is too thin and cannot be manipulated.

Table I Suitable polymers for thermoforming

\begin{tabular}{lccc}
\hline Polymer & $\begin{array}{c}\text { Heat deflection temperature } \\
\text { No load }\left({ }^{\circ} \mathrm{C}\right)\end{array}$ & $\begin{array}{c}\text { Thermoforming temperature } \\
\text { Mold temperature }\left({ }^{\circ} \mathrm{C}\right)\end{array}$ \\
\hline Extruded acrylic & - & $135-175$ & $65-75$ \\
Cell-cast acrylic & - & $160-180$ & $65-75$ \\
Cellulose acetobutyrate & $120-150$ & $140-160$ & - \\
High-density polyethylene & 100 & $145-190$ & 95 \\
Polypropylene & 140 & $145-200$ & $140-170$ \\
Polystyrene & 100 & $170-180$ & $45-65$ \\
High-impact polystyrene & 120 & $220-230$ & $45-65$ \\
SAN & - & $120-180$ & $70-85$ \\
ABS & 95 & $135-175$ & 45 \\
Polyvinyl chloride & 110 & $180-230$ & $95-120$ \\
Polycarbonate & 160 & & \\
\hline
\end{tabular}


Table II Thermoforming temperature ranges

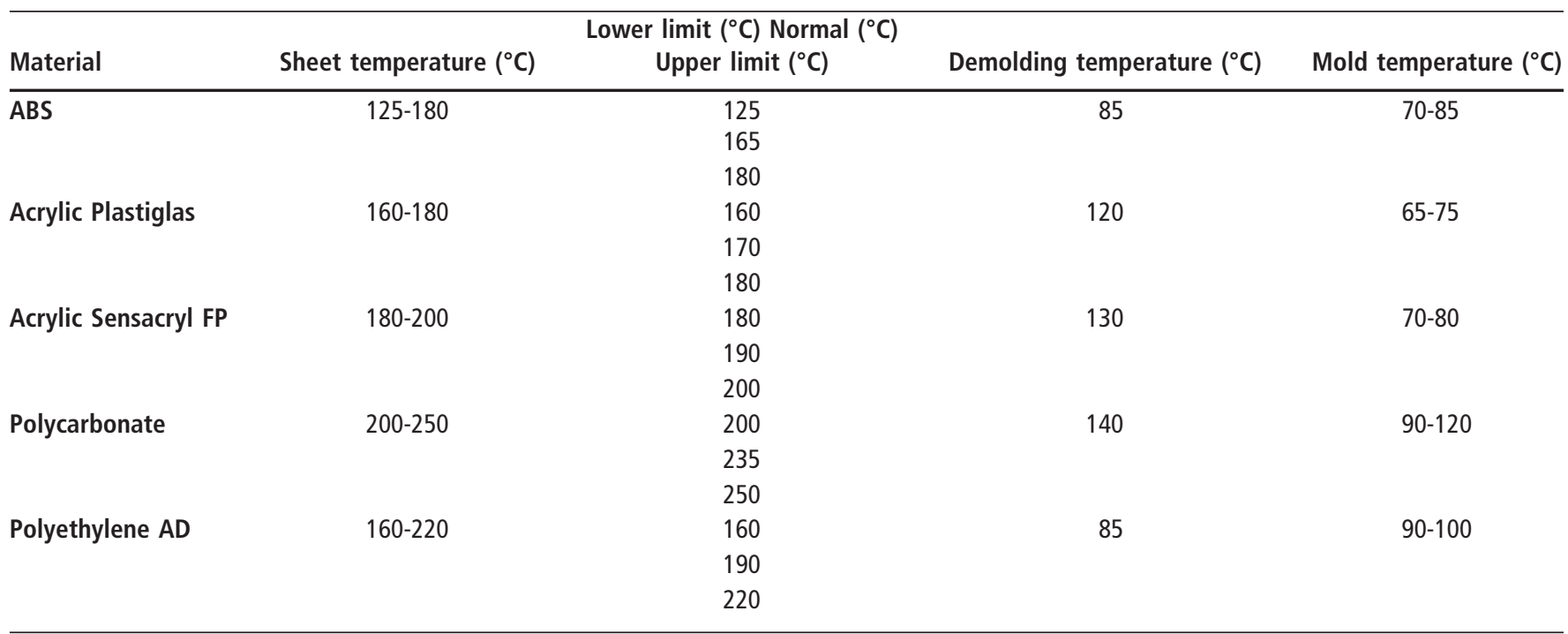

The selection of the thermoforming force depends on the size of the part, its volume and the cycle time. However, other factors that determine the selection of forces to be applied in the manufacturing process are: the inherent limitations of each thermoplastic material, the construction and material of the mold and the thermoforming equipment available (Wolfram et al., 2009).

The basic principle of the vacuum-forming process is to have a softened thermoplastic sheet in a perfectly sealed mold and then evacuate the air by vacuum or suction force. When the air is evacuated from the mold, this causes a negative pressure on the surface of the sheet, and the natural atmospheric pressure therefore forces the heated sheet to fill the shape.

The mold used must take into account the following factors: the shape and dimensions of the part, the desired appearance, the estimated volume of manufacturing and the thermoforming technique. The criteria used in the design of thermoformed parts are:

- Thinning of the material's thickness which depends on the shape, size and technique used. It can be seen that the thinning of the material's thickness is directly proportional to the height of the model. In the case of dental splints, the thermoplastic sheet manufacturers indicate (www.erkodent.com) that for every $1-\mathrm{cm}$ increase in the height of the thermoforming, there is a variation in the material thickness of approximately 25 per cent.

- A demolding angle between $3^{\circ}$ and $5^{\circ}$ should be used.

- A contraction of the part of between 0.6 and 1 per cent on cooling should be taken into account.

- The surface of the thermoformed piece should normally be smooth, although it is possible to obtain a certain texture if desired.

- In the design of the piece, a large radius should be included. It is possible to obtain edges, but this may cause fissures in the material.

\subsection{Test of the splint}

The test conditions for when the splint is fitted in the patient's mouth are as follows:

- the splint should be inserted and removed by the patient, using his or her fingers;

- the patient has a sense having a foreign body in his/her mouth, which usually disappears in a short time;

- the patient may notice some discomfort in areas where the splint is supported, especially at the edges. If this increases or does not diminish, the splint must be corrected by cutting to prevent further friction;

- the splint must be regularly cleaned by brushing with soap or toothpaste. This will prevent the development of bad odors and taste; and

- the splint must be fitted perfectly, to avoid fracturing or injury to the gums.

\section{Results}

\subsection{RP model}

The accuracy of the final model is determined initially by the scanning process, the $3 \mathrm{D}$ virtual modeling and the $\mathrm{RP}$ process.

Figure 2 Errors in the rapid prototyping process

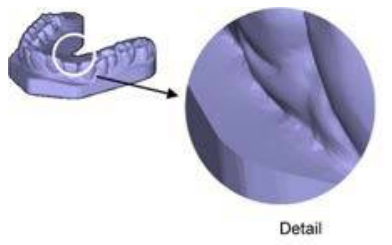

Error in the conversion of $3 D S T L$ model

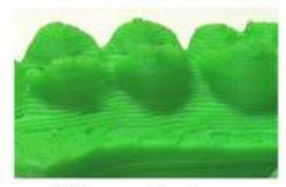

Staircase effect error.

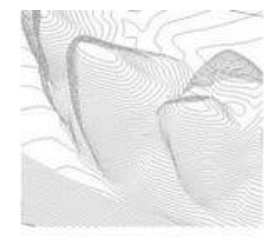

Error decomposition in layers of $3 D$ mode

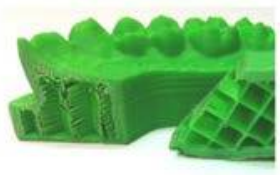

Filling error inside the model. 
Table III Analyzed prototypes

\begin{tabular}{lcc}
\hline Technology & Layer height $(\mathrm{mm})$ & Material \\
\hline SL (VIPER-3D system) & 0.1 & Resin \\
\hline
\end{tabular}

SLS (Formiga P100-EOS)

Injected resin and cured by UV light (Objet-24-30)

SGC (VFlash/PROJET-3D system)

3DP (Spectrum Zcorp 310-450)

FDM (Dimension Elite - stratasys)

Removal of material by milling (Roland DWX 30)
0.1

Polyamide

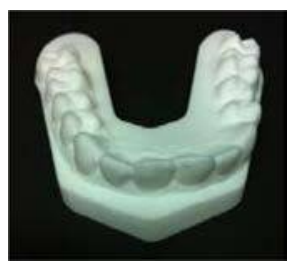

Resin fullcure

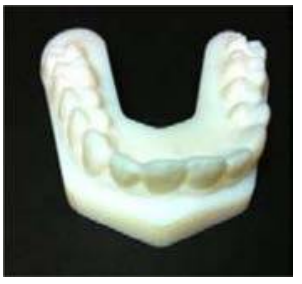

Resin Epoxy-GN

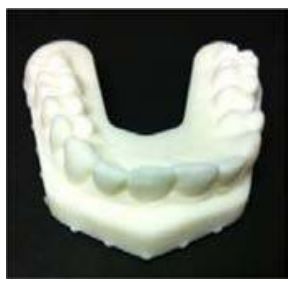

0.1

Composite

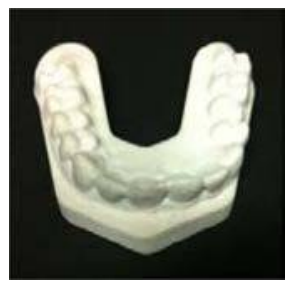

0.178

ABS

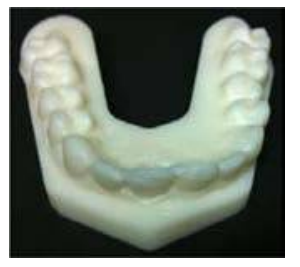

0.1

Necuron 1007

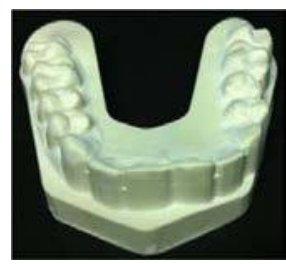


During the RP process, the model is constructed by depositing layers on the XY plane, which thereby acquires solid volume in the direction of the $\mathrm{Z}$-axis. This process is characterized by a volume error between the volume of the virtual $3 \mathrm{D}$ model and the volume of the material obtained in the prototype model, and the precision of the prototyping is therefore the result of the superposition of different errors in the production of the model, which affects the surface quality, the dimensional accuracy and the final weight of the prototype (Weiss et al., 2010).

The errors produced in this process are: an error in converting the 3D STL model (triangulation geometry), another in the decomposition of the $3 \mathrm{D}$ model layers (thickness exact division), a staircase effect error (orthogonal deposition layered material) and, finally, a filling error inside the model (Jamieson and Hacker, 1995; Reeves and Cobb, 1997; Yong et al., 2005; Ahn and Lee, 2007). These errors can be observed in Figure 2, where details of the FDM prototyping models used in this study are presented.

With the objective of analyzing the effect of errors on prototyped models to be used in the thermoforming of splints, several prototypes were manufactured using the most important prototyping technologies (Table III). The models' behavior was checked during the thermoforming process of the splint. After that, the surface and geometry of each model and splint were analyzed to obtain data to determine which prototyping process technology is most suitable for defining the optimum 3D model.

\subsection{Vacuum thermoforming dental activators: tests performed}

The thermoplastic sheet used was made by Erkodent. To facilitate the splint's adjustment to the teeth, there should be an assembly tolerance providing the necessary clearance for a sliding fit of the splint on the teeth. This clearance can be obtained in two ways (Figure 3):

1 using an insulating film originally attached to the thermoplastic sheet; and

2 using a film which is separate from the thermoplastic sheet and has previously been thermoformed on the model.

The characteristics of sheets and films are shown in Table IV.

If the model is made of plaster, the following points should be taken into account:

- the plaster can retain some humidity but should not be wet;

Figure 3 Sheets used in the thermoforming of splints
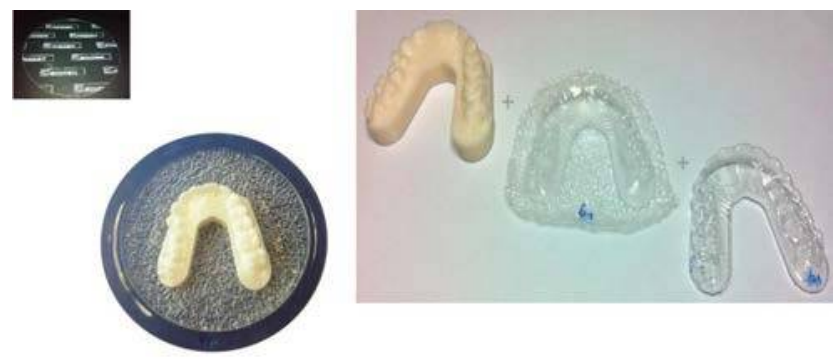

Using insulating film originally attached to the thermoplastic sheet.
Using separated film thermoformed on the model previously to the thermoplastic sheet.
Table IV Characteristics of thermoplastic sheets and films

Thermoplastic sheet
Model

Model

ERKODUR

Thermoplastic sheet (including insulating film)

Material

5212 06/52 4206

PETG: copolyester

$P E$, insulating film: polyethylene

Thermoplastic material with

biocompatibility characteristics (93/42/

(EE). Insoluble in water. Transparent hard plate. Extremely resistant to shock. Easily hollowed out. Combined with self-curing acrylate

Dimensions (mm)

Thermoplastic sheet $/ \varnothing 120 \times 0.6$

Insulating film $/ \varnothing 120 \times 0.03$

Temperature $\left({ }^{\circ} \mathrm{C}\right)$

Warm up: $160^{\circ} \mathrm{C} /$ Time: $40 \mathrm{~s} / \mathrm{Cooling}: 30^{\circ} \mathrm{C}$

and time (s)

Separator film

Model

Material

Dimensions ( $\mathrm{mm})$

Temperature $\left({ }^{\circ} \mathrm{C}\right)$

and time (s)
ERKOTEAM/Separator film

PE: polyethylene

Thermoplastic film $/ \varnothing 120 \times 0.1$

Warm up: $160^{\circ} \mathrm{C} /$ Time: $40 \mathrm{~s} /$ Cooling: $30^{\circ} \mathrm{C}$
- for a good fit, the plaster should be permeable to air. When using air-impermeable models, there is incomplete adjustment of the sheet to the model because not all the air can escape completely from the model and the sheet interface; and

- to limit the height of the thermoforming and achieve rapid adaptation of the model on the base of the thermoforming machine, it is a good idea to press the models onto the granules of steel or lead of the base. This type of base model facilitates an orientation to prevent the tilting that causes variations in the thickness of the ferrule during thermoforming.

As indicated above, the objective of this project was to replace the plaster model with a model obtained by RP and to carry out an analysis to determine ideal prototyping technology for the model.

Once the final model has been obtained using different prototyping techniques, and using a vacuum thermoforming process, the splints are formed from a thermoplastic sheet according to the process described in Tables $\mathrm{V}$ and VI.

The forming process data are presented in Table V. It is interesting to note that the vacuum pressure is not very high (0.7 bar approximately) and that the operating temperatures are completely within the range of normal temperatures for this type of operation.

Note also the orientation of the model on the metal grains which permit a correct positioning of the model before forming.

In Table VI, the different phases of thermoforming can be seen. At the end, the plastic sheet must be cut to custom size to obtain the splint that will be implanted in the patient's mouth. 
Table V Details of the vacuum thermoforming process

Ultrafast vacuum unit (> 0.7 bar)

SPLINT MATERIAL

Position of the heaters

Heating temperature $\left({ }^{\circ} \mathrm{C}\right)$

Heating time (s)

Cooling time (s)

Material separator film

Position of the heaters

Heating temperature $\left({ }^{\circ} \mathrm{C}\right)$

Heating time (s)

Cooling time (s)
ERKOFORM-RVE
ERKODUR - $/ \varnothing 120 \times 0.6$

Top

$160^{\circ} \mathrm{C}$

40-30 s

$30 \mathrm{~s}$

ERKOTEAM - $\varnothing 120 \times 0.1$

Top

$160^{\circ} \mathrm{C}$

$40 \mathrm{~s}$

$20 \mathrm{~s}$
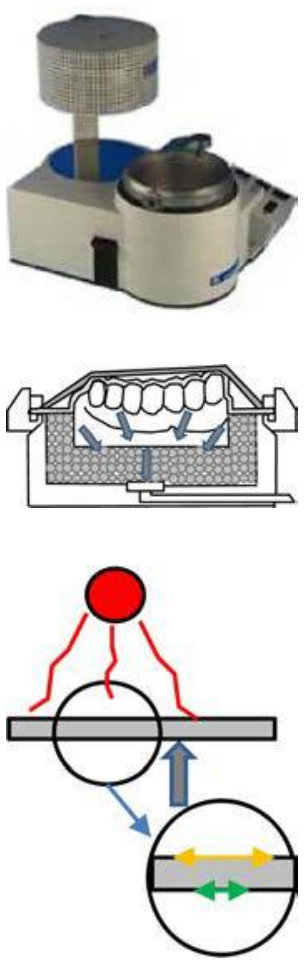

Horizontal manual

0.7 bar

$60 \mathrm{~s}$

$0 \mathrm{~s}$ (during vacuum cooling)

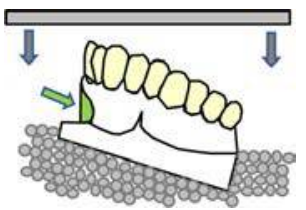

Model finishing

Removal of the model

Removal of the sheet

Cutting excess material

Sanding of edges

Thermoforming height
Immediate-manual

Immediate - manual

Scissors - manual

Rotary sanding

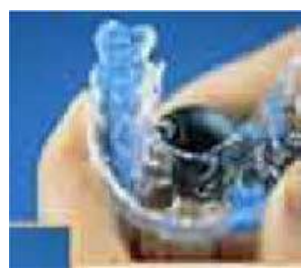

$10 \mathrm{~mm}$

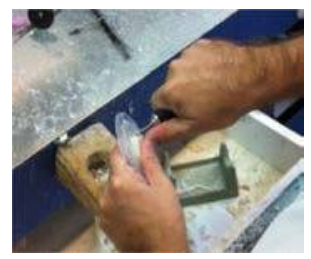

\subsection{Dimensional and geometrical verification of the surface}

In thermoforming, the reduction or shrinkage and the variation of dimensional tolerance are different for parts formed in a male mold and those formed in a female mold. In a male mold, shrinkage can be reduced if the part is cooled slowly in the mold. If cooling takes place to ambient temperature in the mold, the shrinkage is minimal. This situation will result in an internal dimension of the workpiece that will be very close to the dimensions of the mold.

However, when a male mold is used, the part is usually removed while it is still hot to avoid difficulties which may be caused by heat shrinkage, which is the proportional difference between the ambient temperature and the temperature at the 
M. Fiménez et al.

Table VI Phases of the vacuum thermoforming process
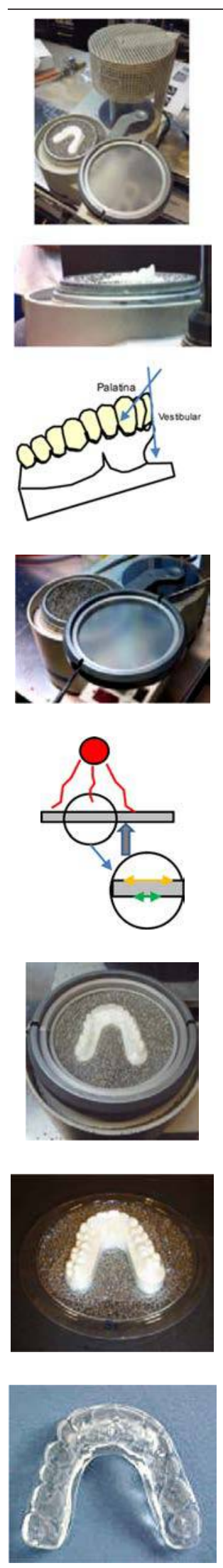

Proper orientation of the model (buccal or lingual inclination) to position the occlusal and incisal faces, both of which can suffer a thickening or thinning, especially in models with undercuts

The thermoplastic sheet is placed in the cradle (including insulating film)

The sheet is placed in the model and the vacuum process (vacuum forming) begins. The sheet adheres to the surface of the model

Positioning the working model (maxilla or mandible) at the base of the thermoformer, supported on a granular lead

The thermoplastic sheet is heated to its softening temperature. Heating is performed by radiation

The sheet is removed manually after cooling and trimmed using a disk-shaped cutting tool so that the tray is perfectly adapted to the patient's jaw

If a separating film is used before the thermoplastic process, the process is repeated in a similar way

\section{Volume $21 \cdot$ Number $1 \cdot 2015 \cdot 56-69$}

time of demolding. If the mold is to be removed while still hot, the dimension-specified part will require a slightly larger model.

On the other hand, with the female mold, the part formed begins to shrink as soon as the temperature of the material is below the molding temperature. To maintain a strict tolerance mold, the dimension must be increased and vacuum pressure must be maintained throughout the operation.

In the case of the models used for the thermoforming of splints, the impact of the model's surface finish on the functional surfaces of the splint must be considered (Figure 4). The adhesion produced between the model and the thermoplastic sheet during vacuum thermoforming produces an accurate footprint surface, and, consequently, the patient feels a scratching sensation when the splint is fitted.

The verification of the variation in thickness of the sheet is also important, especially in areas that are formed at the end of the process. Depending on the position of the model, the increase or decrease in thickness in the occlusal or incisal areas directly affects the properties of the splint, particularly with regard to toughness and resistance to permeability.

For dimensional verification, thickness and the surface quality of the splint, appropriate tests were carried out. The results are shown in Tables VII and VIII.

As can be seen in Table VII, the best quality surface finish on the model is obtained with SLA, while the best quality in splints is obtained with IJP or FDM. The quality obtained with ultraviolet (UV) photopolymerization (SGC) is acceptable, taking the results obtained by the machining procedure as a reference.

Table VIII shows the results obtained when measuring thickness. It can be observed that acceptable results are obtained with practically all the technologies.

Figure 4 shows the results of the tests, in comparative form (Figure 5).

The use of a thermoformed separating film $(0.1 \mathrm{~mm})$, before the thermoplastic sheet thermoforming, causes a decrease in the surface trace of the model on the splint. This

Figure 4 Impact of the finished model on functional surfaces

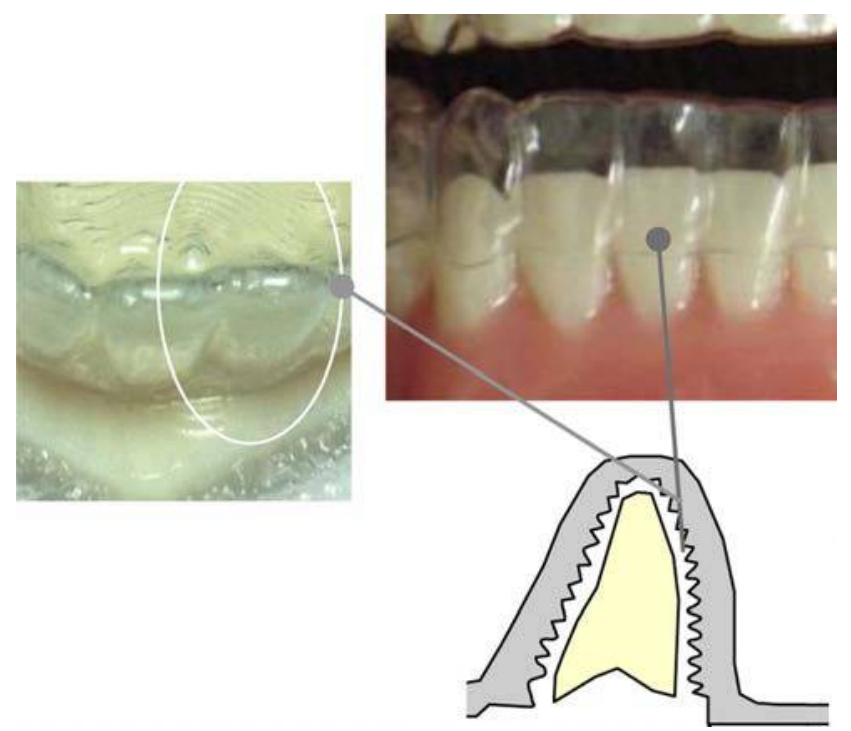


Table VII Verification of surface finish of the splint

Surface finish of the splint
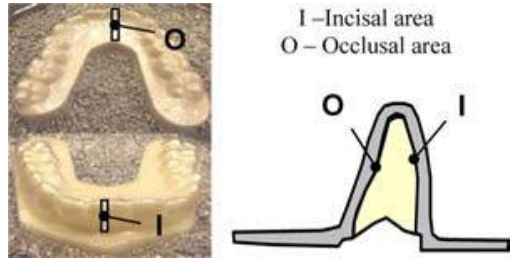

Measures obtained

\begin{tabular}{|c|c|c|c|c|c|c|c|c|}
\hline \multirow[b]{2}{*}{ No. } & \multirow{2}{*}{\multicolumn{2}{|c|}{ Model data }} & \multicolumn{2}{|c|}{ Model } & \multicolumn{2}{|c|}{$\begin{array}{l}\text { Splint with } \\
\text { insulating film }\end{array}$} & \multicolumn{2}{|c|}{$\begin{array}{l}\text { Splint without } \\
\text { insulating film }\end{array}$} \\
\hline & & & I & 0 & $\mathbf{I}$ & 0 & I & 0 \\
\hline 1 & SLA. Layer level: $0.1 \mathrm{~mm}$. Resi & & 1.9 & 3.7 & 1.1 & 2.3 & 1.2 & 2.8 \\
\hline 2 & SLS Layer level: $0.1 \mathrm{~mm}$. Polya & & 14.2 & 15.4 & 3.6 & 4.3 & 3.8 & 6 \\
\hline 3 & IJP. Layer level: $0.1 \mathrm{~mm}$. Resin & & 4.6 & 8.3 & 0.9 & 2.6 & 1.1 & 3.4 \\
\hline 4 & $\begin{array}{l}\text { UV photopolymerization (SGC) } \\
\mathrm{mm} \text {. Resin }\end{array}$ & 0.11 & 12.7 & 18.7 & 2.3 & 2.6 & 3.3 & 4.9 \\
\hline 5 & $\begin{array}{l}\text { 3DP. Layer level: } 0.1 \mathrm{~mm} \text {. Con } \\
\text { infiltrated }\end{array}$ & & 23 & 30 & 4.5 & 5.7 & 8.3 & 7.5 \\
\hline 6 & $\begin{array}{l}\text { 3DP. Layer level: } 0.1 \mathrm{~mm} \text {. Con } \\
\text { Cianocrylate infiltrated }\end{array}$ & & 19 & 25 & 4 & 5.3 & 7 & 6.7 \\
\hline 7 & FDM. Layer level: 0.178 mm. & Solid & 13.5 & 16.5 & 2.5 & 3.4 & 3 & 5.2 \\
\hline 8 & ABS & Hollow & 13 & 24.8 & 2 & 2.7 & 3 & 5 \\
\hline 9 & Milling. Necuron 1007 & & 2.8 & 17.1 & 0.4 & 2.7 & 0.4 & 2.8 \\
\hline
\end{tabular}

Table VIII Verification of the geometrical profile of the splint

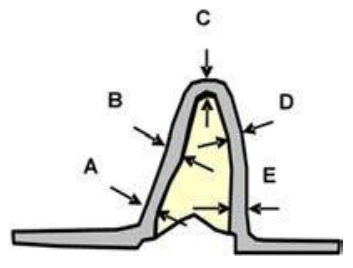

A, B - Occlusal area (palate); C - neutral area; D, E - Incisal (vestibular)

Measures obtained

\begin{tabular}{|c|c|c|c|c|c|c|c|}
\hline \multirow[b]{2}{*}{ No. } & \multirow{2}{*}{\multicolumn{2}{|c|}{ Model data }} & \multicolumn{5}{|c|}{ Thickness of the splint (mm) } \\
\hline & & & A & B & C & D & $\mathrm{E}$ \\
\hline 1 & SLA. Layer level: $0.1 \mathrm{~mm}$. Resin & & 0.50 & 0.54 & 0.47 & 0.42 & 0.34 \\
\hline 2 & SLS Layer level: $0.1 \mathrm{~mm}$. Polyamid & & 0.50 & 0.44 & 0.56 & 0.50 & 0.34 \\
\hline 3 & IJP. Layer level: $0.1 \mathrm{~mm}$. Resin & & 0.48 & 0.47 & 0.46 & 0.37 & 0.25 \\
\hline 4 & UV photopolymerization (SGC). Lay & $0.11 \mathrm{~mm}$. Resin & 0.47 & 0.46 & 0.53 & 0.41 & 0.27 \\
\hline 5 & 3DP1. Layer level: $0.1 \mathrm{~mm}$. Compo & ky infiltrated & 0.53 & 0.44 & 0.46 & 0.40 & 0.27 \\
\hline 6 & $\begin{array}{l}\text { 3DP2. Layer level: } 0.1 \mathrm{~mm} \text {. Compo } \\
\text { infiltrated }\end{array}$ & ocrylate & 0.51 & 0.41 & 0.43 & 0.39 & 0.25 \\
\hline 7 & FDM. Layer level: $0.178 \mathrm{~mm}$. ABS & FDM1 Solid & 0.48 & 0.45 & 0.42 & 0.37 & 0.26 \\
\hline 8 & & FDM2 Hollow & 0.42 & 0.44 & 0.45 & 0.35 & 0.21 \\
\hline 9 & Milling. Necuron 1007 & & 0.50 & 0.43 & 0.48 & 0.48 & 0.34 \\
\hline
\end{tabular}


Figure 5 Verification of surface finish of the model

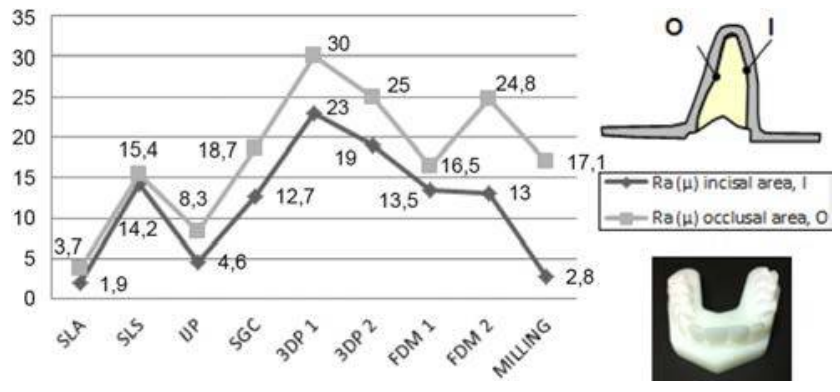

improvement is appreciably greater than that obtained with the use of an affixed insulating film $(0.03 \mathrm{~mm})$.

Another added advantage is the clearance obtained by the use of the separating film between the splint and the teeth. This results in a faster and more comfortable fit in the patient's mouth, without affecting its properties (Figures 6 and 7).

With regard to the variation in the thickness of the splint, the least variation in thickness in the incisal area is obtained by SLS, while in the occlusal area, it is caused by SLA, as can be seen in Figure 8.

\subsection{Prototyping costs}

With the aim of calculating the price of an item manufactured by RP technologies, the recommendations made by several authors (Xu et al., 2000; Lan and Ding, 2007; Grimm TA \& Associates, 2010 and Pereira et al., 2010) were taken into account.

The final prototype manufacturing cost $(\mathrm{Cp})$ of the $3 \mathrm{D}$ model supplied was calculated using the formula:

$$
\mathrm{C}_{\mathrm{p}}=\mathrm{C}_{\mathrm{t}}+\mathrm{C}_{\mathrm{e}}+\mathrm{C}_{\mathrm{m}}+\mathrm{C}_{\mathrm{a}}
$$

where, $C_{t}=$ cost of the preparation of the $3 \mathrm{D}$ model, including the reading and orientation of the STL file; $\mathrm{C}_{\mathrm{e}}=$ cost of implementation, including operator, machine and maintenance cost; $\mathrm{C}_{\mathrm{m}}=$ cost of materials used, including the cost of the support trays and of the materials used to make the mold; and $\mathrm{C}_{\mathrm{a}}=$ cost of post-manufacturing processes, including manual and automatic cleaning.

The data obtained for the manufacturing of the model by prototyping technologies are shown in Table IX.

The thermoforming of the splints is traditionally carried out on dental models that have been manufactured in plaster. This is the reason why the comparison between the costs incurred and the costs traditionally incurred is important. The costs of technologies such as SLA and SLS were greater than the traditional costs, while the other technologies provided certain cost advantages.

For the evaluation of the cost of the different technologies, it must be borne in mind that the comparison of technologies is limited by the type of machine used. In this study, it has been assumed that prototyping machines based on SLA and SLS have an industrial prototyping application (need a custom installation), while the rest are considered professional application machines (can be installed in any space), where mass production is not the main objective.
Figure 6 Verification of surface finish of the splint with insulating film

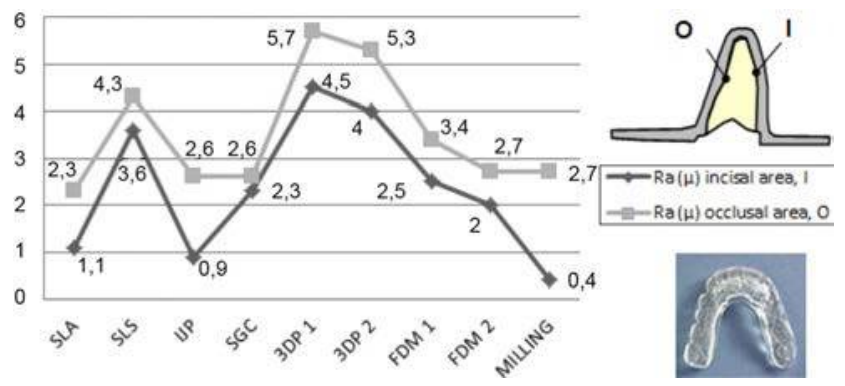

Figure 7 Verification of surface finish of the splint without insulating film

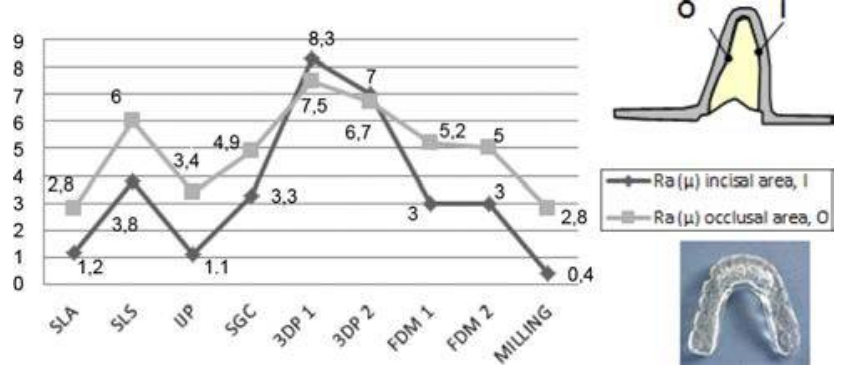

For the purposes of comparison, the costs of the prototyping of one model or $n$ models, where $n$ is the ideal number for each area prototyping machine (Figure 9), have been calculated.

If there is a single prototype model or a certain number of prototype models, the smallest cost is produced by the FDM in a hollow model and UV photopolymerization (SGC).

In terms of the relationship between surface finish and thickness reduction and the cost of the model (Figure 10), the most appropriate technologies for prototyping models for thermoform manufacturing of correction splints are IJP, UV photopolymerization (SGC) and FDM.

\subsection{Test results of splints in the patient's mouth}

Functionality and assembly tests were carried out on eight patients, with five splints per patient and at intervals of roughness of $5,10,15,20$ and $25 \mu$.

It was observed that the maximum average roughness admissible in the splint that does not cause a sensation of irritation in the patient's mouth during fitting is $\mathrm{Ra}=20 \mu$.

\section{Discussion}

One method of straightening teeth in a short period of time at a reduced cost is through the use of occlusal splints.

A very useful way of obtaining splints is via a vacuum pressure thermoforming process which uses a physical model obtained from a particular prototyping technology. But it is important to note that the technology used to generate the model determines the quality of the splint in terms of dimensional accuracy, surface quality, thickness variation and, of course, cost.

The use of a dental model manufactured by RP technologies makes the replacement of traditional models 
Figure 8 Variations in the thickness of the splint

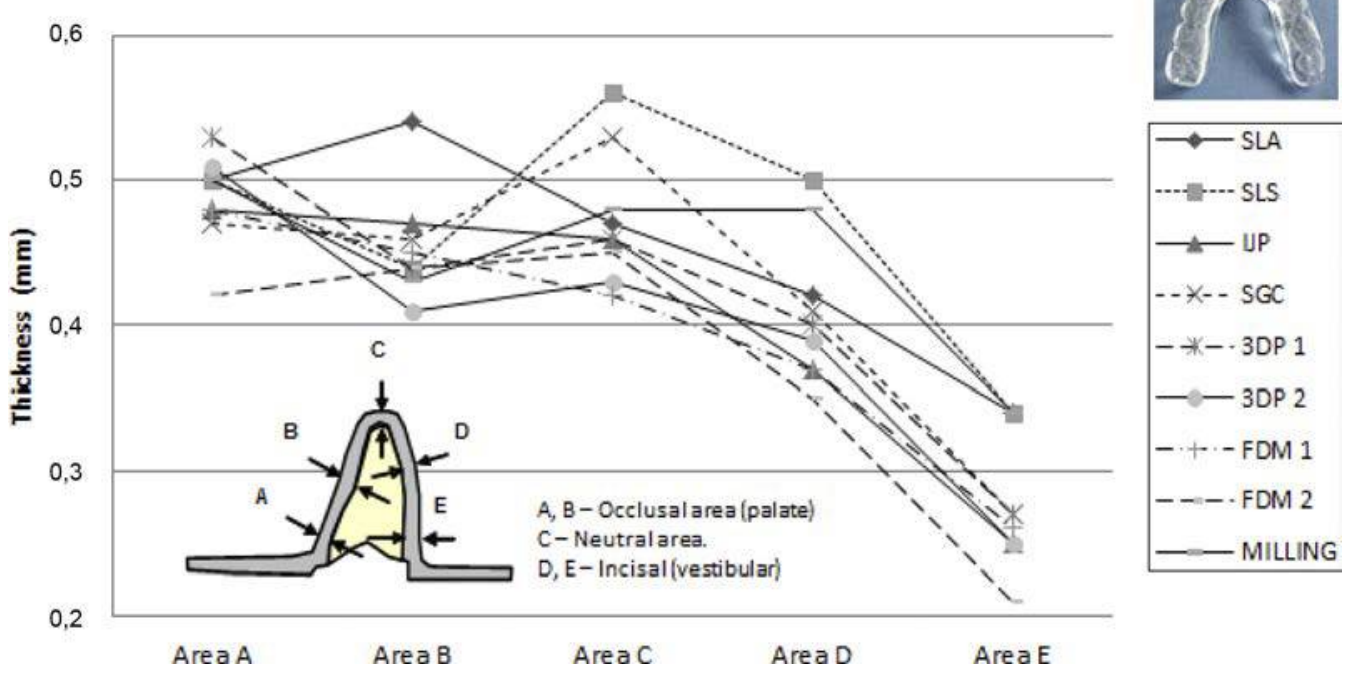

which use plaster manufacturing technologies possible. The production process for this plaster model is slow and laborious, as any distortion of the holding material must be avoided, an appropriate mix of water to powder must be obtained, the separation of the model from the mold must be effected at the right moment and there must be no bubbles in the mold because this could affect strength.

Although the unit cost of the plaster dental models is lower than the cost of the prototyped dental models, traditional models require the actual position of the teeth to be established by taking an impression of the patient's mouth, which is subsequently used to obtain a dental model.

A key advantage of the RP of this type of model with respect to conventional technologies is the direct integration of this

Table IX Final cost of the prototypes tested

\begin{tabular}{|c|c|c|c|}
\hline No. & Data of the model & Prototype & $\begin{array}{l}\text { ost per unit } \\
\text { E) } \\
\text { Quantity: N } \\
\text { models } \\
\text { (ideal) }\end{array}$ \\
\hline \multicolumn{4}{|c|}{ Prototyping industrial machines } \\
\hline 1 & SLA. Layer level: $0.1 \mathrm{~mm}$. Resin & 51 & 34 \\
\hline 2 & $\begin{array}{l}\text { SLS. Layer level: } 0.1 \mathrm{~mm} \text {. } \\
\text { Polyamide }\end{array}$ & 63 & 40 \\
\hline \multicolumn{4}{|c|}{ Prototyping professional machines } \\
\hline 3 & IJP. Layer level: $0.1 \mathrm{~mm}$. Resin & 45 & 30 \\
\hline 4 & $\begin{array}{l}\text { UV photopolymerization (SGC-FTI). } \\
\text { Layer level: } 0.11 \mathrm{~mm} \text {. Resin }\end{array}$ & 25 & 21 \\
\hline 5 & $\begin{array}{l}\text { 3DP1. Layer level: } 0.1 \mathrm{~mm} \text {. } \\
\text { Composite. Epoxy }\end{array}$ & 35 & 22 \\
\hline 6 & $\begin{array}{l}\text { 3DP2. Layer level: } 0.1 \mathrm{~mm} \text {. } \\
\text { Composite. Cianocrylate }\end{array}$ & 39 & 26 \\
\hline 7 & FDM. Layer level: $\quad$ FDM1 Solid & 27 & 24 \\
\hline 8 & $0.178 \mathrm{~mm} . \mathrm{ABS} \quad$ FDM2 Hollow & 19 & 14 \\
\hline 9 & Milling. Necuron 1007 & 85 & 70 \\
\hline
\end{tabular}

Figure 9 Final cost of the prototypes tested

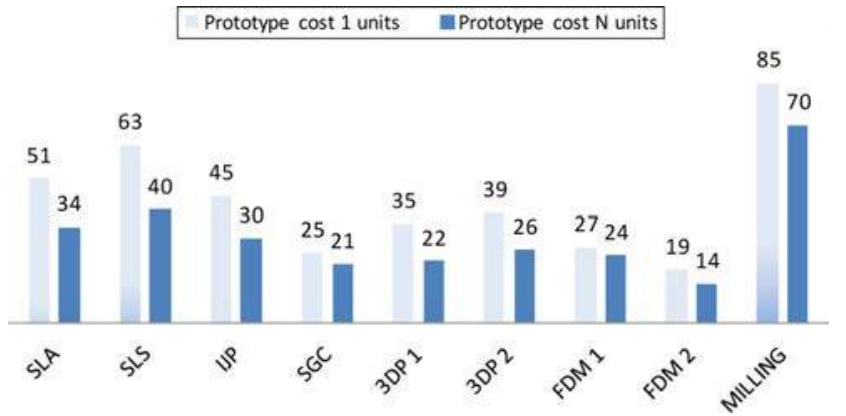

prototyping phase into the new digital processes of oral implantology. This process is based on the use of digital resources in both the prosthetic and the clinical phases. The data generated during the intraoral scanning and their subsequent analysis by CAD systems mean that the technology can produce models more quickly and with significant cost savings, as well as a reduction in the number of patient appointments.

The only disadvantage attaching to the utilization of this new method, which is worthy of note, is that it requires the use of a CAD dental system for the detection and manipulation of those points which require some correction and for the simulation of the treatment plan required.

If the models are digitally processed, prototypes are obtained in less time. In addition, given the wide range of available materials, they can be adapted to any requirement in terms of strength, dimensional, geometric or surface precision.

The thermoforming of the occlusal splints was carried out on a vacuum machine normally used in prosthetic laboratories, which responds to the need for a medium production volume. The level of vacuum pressure and temperature is static, and its variation and adaptation for different materials were not studied in this research, as their effects on the surfaces of the splint, and especially with respect 
Figure 10 Comparative RP technologies of model for the thermoform manufacturing of dental activators (splints)
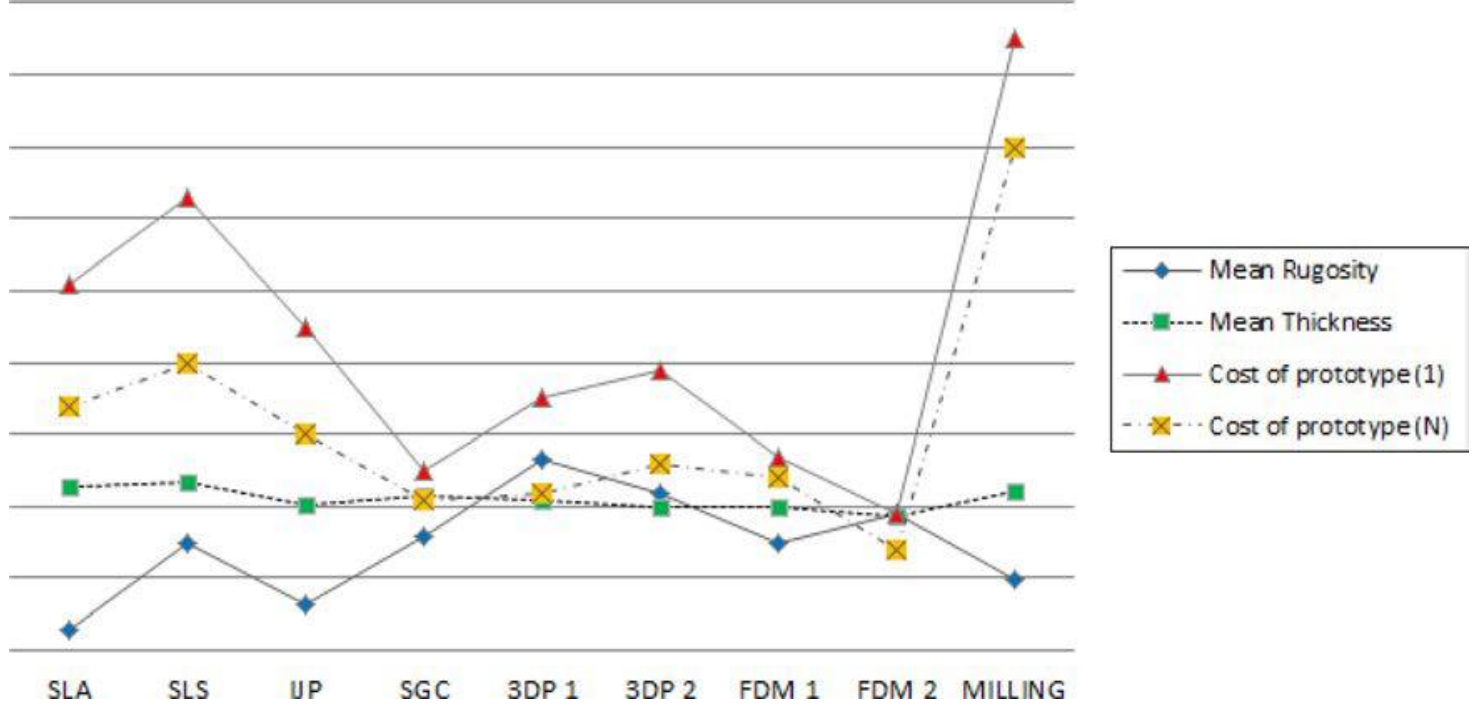

to the thinning of the thickness of the material, were considered to be minimal.

With regard to the dimensional and geometrical verification of the surface, the decrease in the thickness of the splint in those areas which have a corrective effect on the teeth were analyzed.

As mentioned above, shrinkage of the material during the cooling is avoided through the use of a separating film. This film makes an improvement in the surface finish possible, eliminating unwanted textures and facilitating the mounting of the splint onto the teeth.

This research was carried out on splints with a thickness of $0.6 \mathrm{~mm}$, whose healing effects have been validated through tests on patients. However, tests could also be carried out on splints of a greater thickness to determine their behavior during thermoforming and in the patient's mouth.

No significant limitations in the performance of the splint due to variations in thickness during the process of thermoforming have been detected. On the basis of patient feedback, it would appear that the use of a separating layer in this process is largely successful in correcting the average error in most dimensions which results from the use of RP in the production of models.

By means of an analysis of the most important variables (prototype material, dimensional accuracy, surface finish and cost prototyping), this research project represents an advance in terms of the selection of the optimal prototyping technology for the manufacture of occlusal splints.

\section{Conclusion}

The results obtained in the project, and as shown in this paper, lead the authors to suggest that there is a group of prototyping technologies suitable for the manufacture of the models used in the thermoforming of correction splints, the most appropriate being the technologies based on IJP, UV photopolymerization (SGC) and FDM because of the optimal relationship between the cost and the quality of the model required for thermoforming.
Future lines of research will focus on the use of thermoplastic sheets with greater thicknesses to determine the maximum thickness of the splint. Thus, it will be possible to analyze the characteristics of the prototype and the smoothness of the functional surfaces of the model. In addition, it will analyze the forces generated during the thermoforming process and their relationship with other alternative designs for the RP models.

According to preliminary tests carried out, the thickness limit for such splints is around $0.8-1 \mathrm{~mm}$. In addition, there exists the possibility of improving the surface finish of prototyped surfaces (smoothing) without significant dimensional changes, raising the possibility of using prototyping technologies for thermoformed splints that are not currently viable.

\section{References}

Ahn, D.K. and Lee, S.H. (2007), "Improving the surface roughness of SL parts using a coating and grinding process", International foumal of Precision Engineering and Manufacturing, Vol. 8 No. 3, pp. 14-19.

Ayhan, Z. and Zhang, Q.H. (2000), "Wall thickness distribution in thermoforming food containers produced by a Benco Aseptic packaging machine", Polvmer Engineering and Science, Vol. 40 No. 1, pp. 1-10.

Azari, A. and Nikzad, S. (2009), "The evolution of rapid prototyping in dentistry: a review", Rapid Prototyping fournal, Vol. 15 No. 3, pp. 216-225.

Boyd, R.L. and Vlascalic, V. (2001), "Three-dimesional diagnosis and orthodontic treatment of complex malocclusions with the Invisalign appliance", Seminars in Orthodontics, Vol. 7 No. 4, pp. 274-293.

Delorenzi, H.G. and Nied, H.F. (1987), "Blow molding and thermoforming of plastics: finite element modeling", Composite Structures, Vol. 26 Nos 1/2, pp. 197-206.

Germani, M., Raffaeli, R. and Mazzoli, A. (2010), “A method for performance evaluation of RE/RP systems in dentistry", Rapid Prototvping Fournal, Vol. 16 No. 5, pp. 345-355. 
Gracco, A., Mazzoli, A., Raffaeli, R. and Germani, M. (2008), "Evaluation of 3D technologies in dentistry", Progress in Orthodontics, Vol. 8 No. 1, pp. 26-37.

Grimm TA \& Associates (2010), 3D Printer Benchmark, European Edition, Edgewood, KY.

Hope, R.L., Jacobs, P.A. and Roth, R.N. (1997), "Rapid prototyping with sloping surfaces", Rapid Prototvping Fournal, Vol. 3 No. 1, pp. 12-19.

Hosseini, H., Vasilivich, B.B. and Mehrabani-Zeinabad, A. (2006), "Modeling of deformation processes in vacuum thermoforming of a pre-stretched sheet", Polvmer-Plastic Technology and Engineering, Vol. 45 No. 12, pp. 1357-1362.

Jamieson, R. and Hacker, H. (1995), "Direct slicing of CAD models for rapid prototyping", Rapid Prototyping fournal, Vol. 1 No. 2, pp. 4-12.

Kwon, T.-G., Mori, Y. and Minami, K. (2002), "Reproducibility of maxillary positioning in Le Fort I osteotomy: a 3-dimensional evaluation", fournal of Oral Maxillofacial Surgerv, Vol. 60 No. 3, pp. 287-293.

Lan, H. and Ding, Y. (2007), "Price quotation methodology for stereolithography parts based on STL model", Computers and Industrial Engineering, Vol. 52 No. 2, pp. 241-256.

Liu, Q., Leu, M.C. and Schmitt, S.M. (2006), "Rapid prototyping in dentistry: technology and application", International Fournal of Advanced Manufacturing Technologv, Vol. 29 No. 3, pp. 317-335.

Masood, S.H. and Soo, A. (2002), "A rule based expert system for rapid prototyping system selection", Robotics and Computer-Integrated Manufacturing, Vol. 18 Nos 3/4, pp. 267-274.

Nam, G.J., Ahn, K.H. and Lee, J.W. (2000), "Three dimensional simulation of thermoforming process and its comparison with experiments", Polvmer and Engineering Science, Vol. 40 No. 10, pp. 2232-2240.

Pereira, C., Calandrin, R., Rosa, B., Oliveira, E., Gomes, E. and Tavares, R. (2010), "Systematic proposal to calculate price of prototypes manufactured through rapid prototyping an FDM 3D printer in a university lab", Rapid Prototuping fournal, Vol. 16 No. 6, pp. 411-416.

Reeves, P.E. and Cobb, R.C. (1997), "Reducing the surface desviation of stereolithography using in-process techniques", Rapid Prototyping fournal, Vol. 3 No. 1, pp. 20-31.

Taft, R.M., Kondor, S. and Grant, G.T. (2011), "Accuracy of rapid prototype models for head and neck reconstruction", 7ournal of Prosthetic Dentistry, Vol. 106 No. 6, pp. 399-408.

Throne, J.L. (1987), Thermoforming, Hanser Publishers, Munich.

Vargas, H.L. and Córdoba, N.E. (2004), "Calidad superficial en el prototipado rápido, proceso FDM", Ingeniería e Investigación, Vol. 24 No. 3, pp. 28-32.

Weiss, E., Pajak, E., Kowalski, M., Wichniarek, R., Zawadzki, P., Dudziak, A., Paszkiewicz, R. and Gorski, F. (2010), "Accuracy of parts manufactured by rapid prototyping technology", Annals of DAAAM E Proceedings of the 21st International DAAAM Symposium, Vol. 21 No. 1.

Wolfram, H., Henning, D., Fialka-Fricke, J., Fricke-Zech, S., Zapf, A., Kubein-Meesenburg, D. and Sadat-Khonsari, R. (2009), "Influence of thermoplastic appliance thickness on the magnitude of force delivered to a maxillary central incisor during tipping", American foumal of Orthodontics and Dentofacial Orthopedics, Vol. 136 No. 1, pp. 12.e1-12.e7.

$\mathrm{Xu}, \mathrm{F}$., Wong, Y.S. and Loh, H.T. (2000), "Toward generic models for comparative evaluation and process selection in rapid prototyping and manufacturing", fournal of Manufacturing Svstems, Vol. 19 No. 5, pp. 283-296.

Yanping, L., Shilei, Z., Xiaojun, C. and Chengtao, W. (2006), "A novel method in the design and fabrication of dental splints based on 3D simulation and rapid prototyping technology", International fournal of Advanced Manufacturing Technologv, Vol. 28 Nos 9/10, pp. 919-922.

Yong, Y., Jerry, Y.H., Fuh, H., Tong, L. and Yoke, S.W. (2005), "Minimizing staircase errors in the orthogonal layered manufacturing system", IEEE Transactions on Automation Science and Engineering, Vol. 2 No. 3, pp. 276-284.

Yongnian, Y., Li, S., Zhang, R., Lin, F., Wu, R., Lu, Q., Xiong, Z. and Wang, X. (2009), "Rapid prototyping and manufacturing technology: principle, representative technics, applications, and development trends", Tsinghua Science and Technology, Vol. 14 No. S1, pp. 1-12.

\section{Corresponding author}

L. Romero can be contacted at: 1romero@ind.uned.es

For instructions on how to order reprints of this article, please visit our website: www.emeraldgrouppublishing.com/licensing/reprints.htm Or contact us for further details: permissions@emeraldinsight.com 